\title{
Evidence of percutaneous coronary intervention in patients with coronary disease: clinical nursing practice
}

\begin{abstract}
The research allowed to investigate the evidence of percutaneous coronary intervention in patients with coronary artery disease to support clinical nursing practice. This study suggests that percutaneous coronary intervention is the reperfusion strategy of choice in patients with STEMI when performed by an experienced team on time. May present better results when compared to thrombolytic therapy and facilitated percutaneous coronary intervention, while optimizing the access and use of this type of intervention is necessary. The study demonstrated that primary percutaneous coronary intervention has greater evidence when compared to other therapies.
\end{abstract}

Keywords: coronary artery disease, myocardial infarction, myocardial reperfusion, angioplasty, nurse

\author{
Volume 6 Issue 2 - 2019 \\ Marcel Ricardo Chiarini de Oliveira,' Daniela \\ de Araújo Gian Grossi, ${ }^{2}$ Ana Lucia Gargione \\ Galvão Sant Anna, ${ }^{3}$ Regimar Carla Machado ${ }^{4}$ \\ 'Specialist in Nursing in Critical Care/Cardiology, Federal \\ University of São Carlos, Brazil \\ ${ }^{2}$ Specialist in Intensive Care Nursing with emphasis in Clinical \\ and Surgical Cardiology, Federal University of São Carlos, Brazil \\ ${ }^{3}$ Master in Biomedical Engineering, Federal University of São \\ Carlos, Brazil \\ ${ }^{4} \mathrm{PhD}$ in Sciences by the Graduate Program in Cardiovascular \\ Surgery, Federal University of São Carlos, Brazil
}

Correspondence: Regimar Carla Machado, Federal University of São Carlos, Highway Washington Luís, Km 235-PO Box 676, Brazil,Email regimarmachado@gmail.com

Received: August 12, 2017 | Published: March 21, 2019

\section{Introduction}

In Brazil, cardiovascular diseases occupy the first place in the causes of death, ${ }^{1,2}$ Corresponding to the third largest responsible for hospitalizations and causing about $32.0 \%$ of deaths in the country. ${ }^{3}$ Acute coronary syndromes are clinical signs and symptoms caused by coronary obstruction due to the presence of vulnerable atherosclerotic plaque, which causes myocardial ischemia. ${ }^{3-5}$

Studies show that in 2020, acute coronary syndrome will cause about $40 \%$ of deaths, with the main cause of acute myocardial infarction, ${ }^{3,4}$ Which may occur under two distinct types observed by means of the electrocardiogram examination comprising acute and non-elevated myocardial infarction of the supra ST segment. Patients with total obstruction of a coronary vessel may present with acute myocardial infarction (AMI) with supra ST (SST). ${ }^{6}$

The effectiveness of hospital care and the reduction of mortality in patients with AMI with SST depend on factors such as diagnosis in the emergency department and the rapidity of vessel clearance. The time interval between the admission of the patient in a prompt care and the reopening of the occluded vessel is called the balloon time, which must be less than or equal to 90 minutes. $^{7}$ Intra-hospital treatments include reperfusion therapies, which are performed by chemical interventions (use of fibrinolytics) or mechanical (percutaneous coronary intervention, revascularization). ${ }^{8}$

Regarding the mechanical interventions of acute myocardial infarction with supra ST, there is an increasing use of percutaneous coronary intervention (10), which presents an excellent option to obtain coronary reperfusion when started within the time of the balloon, being Capable of restoring coronary flow in more than $90.0 \%$ of patients, reducing mortality, reinfarction and stroke. ${ }^{8}$
Primary percutaneous coronary intervention is characterized by the use of a balloon catheter or coronary stent implantation, without previous use of fibrinolytic, in order to mechanically restore anterograde coronary flow. ${ }^{3,8}$ Percutaneous coronary intervention is divided into primary when no previous use of fibrinolytics has occurred; facilitated, in which the previous use of fibrinolytics; and salvage therapy, which is used when treatment with fibrinolytics did not achieve the expected result. ${ }^{9}$

In order to be successful in the care of patients with Coronary Artery Disease, a specialized nursing team is needed, mainly for the early diagnosis (electrocardiogram) and the beginning of the interventions. Thus, the objective was to investigate the evidence of primary percutaneous coronary intervention in patients who presented coronary artery disease to support the clinical practice of the nurse.

\section{Percutaneous coronary intervention}

A meta-analysis has shown that PCI reduces short-term mortality, reinfarction, and stroke in comparison to fibrinolysis, ${ }^{10}$ Confirming the results of the present study, even fibrinolytic therapy resulting in up to $50 \%$ reduction in mortality if administered within 3 hours after the onset of symptoms. ${ }^{11}$

In the study ${ }^{12}$ published in 2013, it was found that a strategic alignment of pre-hospital fibrinolysis and antithrombotic cotherapy with timely cineangiocoronariography resulted in effective reperfusion in patients with ST-segment elevation myocardial infarction who presented within 3 hours after the onset of symptoms and who could not undergo PCI within 1 hour of first medical contact. However, fibrinolysis was associated with a slightly increased risk of intracranial hemorrhage compared to the group treated with primary PCI. It is worth noting that this study did not include patients who 
underwent primary PCI less than one hour after the first medical contact and this may be a limitation of the study that favors the results in relation to the group treated with early fibrinolytic therapy, but which may be Consistent with the reality of the Brazilian health system, where logistics and structure hardly allow immediate access to primary PCI for patients with AMI with ST segment elevation.

In a Danish study, ${ }_{13}^{13}$ a delay time for primary PCI of 0 to 60 minutes $(n=347)$ corresponded to a long-term mortality rate of $15.4 \%(n=43)$; A delay of 61 to 120 minutes $(n=2643)$ with a rate of $23.3 \%(n=380)$; A delay of 121 to 180 minutes $(n=2092)$ with a rate of $28.1 \%(n=378)$; And a delay of 181 to 360 minutes $(n=1127)$ at a rate of $30.8 \%(n=275)$ $(\mathrm{p}<0.001)$.

However, it is known that in Brazil a minority of cases is executed in such a way and there are many reasons for the delay and the inadequate functioning of this system. In addition, there is still a frequent delay in the arrival of the patient to the hemodynamic service, mainly due to lack of logistics (transport unfeasibility, inadequate road network, difficulty access, chaotic traffic) or long distance between patient and care. Dedicated and dedicated hospitals often only adhere only partially to infarct care protocols and/or fail to qualify the care system, a situation that is most critical outside business hours. In addition to this, we also have a poor distribution of specialized centers over the national territory. ${ }^{14}$

It can be inferred that the greatest challenge regarding the treatment of AMI is to make the use of primary PCI more widely available, since it is a less invasive and efficient technique, which brings a rapid recovery, decreasing long-term institution expenses Of hospitalization (in cases of delayed search for patients with AMI), in addition to the earlier re-inclusion of the patient in the society. For this, there should be expansion of specialized hemodynamic sectors and optimization of the education of the population regarding the signs/symptoms of AMI, as well as the creation of an ample transfer system in order to attend the community.

\section{Implications for nurses' clinical practice}

Evidence-based practice is characterized by the "conscious, explicit, and judicious use of the best current evidence for decisionmaking about individual patient care"13 making it possible to implement interventions that meet the individual's real needs and encourage the search for scientific knowledge. In this sense, the nurse practitioner performs his function by making a decision focused on caring, knowledge, responsibility, concern and interaction, aiming at the therapy and the solution of the individual's needs, be it in the prevention, curative or rehabilitation. ${ }^{3,4,15}$ On the other hand, besides the care, the nurse performs educational activities and needs theoretical knowledge in order to promote health.

\section{Conclusion}

The nurse performs important functions in the periods considered pre, intra and post procedure. In the period before the intervention, it has an important role in describing the procedure to the patient, in the orientation regarding fasting, puncture of venous access. During the procedure, the organization of the room in which it will be performed, monitoring the patient's vital signs. After the intervention, the nurse performs guidelines for absolute rest in the bed, maintenance of the compressive dressing, investigation of the signs of poor perfusion of the member, in which the angioplasty was performed, monitoring of the vital signs, and being available for possible doubts.

\section{Acknowledgments}

Thank you to the woman involved in the case study, thank you for your confidence.

\section{Conflicts of interest}

The authors report no conflicts of interest.

\section{References}

1. Ishitani LH, Franco GC, Perpétuo IHO, et al. Socioeconomic inequalities and premature mortality due to cardiovascular diseases in Brazil. Rev Saúde Pública. 2006;40(4):684-691.

2. Godoy MF, Lucena JM, Miquelin AR, et al. Cardiovascular Mortality and its Relation to Socioeconomic Levels among Inhabitants of São José do Rio Preto, São Paulo State, Brazil. Arq Bras Cardiol. 2007;88(2):200-206.

3. Pedrolo E, Schneider F, Pott FS, et al. Clinical research in nursing: contributions for technological innovation. Rev Min Enferm. 2012;16(3):445-453.

4. Lemos KF, Davis R, Moraes MA, et al. Prevalence of risk factors for acute Coronary Syndrome in patients treated in an emergency. Rev Gaúcha Enferm. 2010;31(1):129-135.

5. Dessotte CAM, Dantas RAS, Schmidt A. Patients' symptoms before a first hospitalization due to acute coronary syndrome. Rev Esc Enferm USP. 2011;45(5):1097-1104.

6. Pesaro AEP, Campos PCGD, Katz M, et al. Acute Coronary Syndromes: Treatment and Risk Stratifi cation. Rev Bras Ter Intensiva. 2008;20(2):197-204.

7. Albuquerque GO, Szuster E, Corrêa LCT, Goulart E, Souza AC, Sobrinho ALOA, et al. Analysis of the Results of Care for Patients with Acute Myocardial Infarction with ST segment depression during the Daytime and Nocturnal Periods. Rev Bras Cardiol Invas. 2009;17(1):52-57.

8. Tepe G, Schnorr B, Albrecht T, et al. Angioplasty of Femoral-Popliteal Arteries With Drug-Coated Balloons 5-Year Follow-Up of the THUNDER Trial. JACC: Cardiov Int. 2015;8(1):102-108.

9. Greig D, Corbalán $\mathrm{R}$, Castro $\mathrm{P}$, et al. Impacto de la trombolisis y de la angioplastia primaria en pacientes con infarto agudo del miocardio tratados en centros hospitalarios terciarios. Rev Méd Chile. 2008;136(9):1098-1106.

10. Weaver WD, Simes RJ, Betriu A, et al. Comparison of primary coronary angioplasty and intravenous thrombolytic therapy for acute myocardial infarction: a quantitative review. JAMA. 1997;278(23):2093-2098.

11. Boersma E, Maas AC, Deckers JW, et al. Early thrombolytic treatment in acute myocardial infarction: reappraisal of the golden hour. Lancet. 1996;348(9030):771-775.

12. Armstrong PW, Gershlick AH, Goldstein P, et al. Fibrinolysis or Primary PCI in ST-Segment Elevation Myocardial Infarction. $N$ Engl J Med. 2013;368:1379-1387.

13. Terkelsen CJ, Sørensen JT, Maeng M, et al. System Delay and Mortality Among Patients With STEMI Treated With Primary Percutaneous Coronary Intervention. JAMA. 2010;304(7):763-771.

14. Bhatt NS, Solhpour A, Balan P, et al. Comparison of In-Hospital Outcomes With Low-Dose Fibrinolytic Therapy Followed by Urgent Percutaneous Coronary Intervention Versus Percutaneous Coronary Intervention Alone for Treatment of ST-Elevation Myocardial Infarction. Am J Cardiol. 2013;111(11):1576-1579.

15. Young S. Coronary angioplasty: Patient management and nursing care. British J of Cardiac Nursing. 2014;9(9):430-435. 